\title{
1 The Amazon River microbiome, a story of humic carbon.
}

3 Sylvain, François-Étienne ${ }^{1}$; Bouslama, Sidki ${ }^{1}$; Holland, Aleicia ${ }^{2}$; Leroux, Nicolas ${ }^{1}$; Mercier,

4 Pierre-Luc ${ }^{1}$; Val, Adalberto Luis ${ }^{3}$; Derome, Nicolas ${ }^{1}$

1. Institut de Biologie Intégrative et des Systèmes, Université Laval, 1030 avenue de la Médecine, Québec (QC), G1V 0A6, Canada

2. La Trobe University, School of Life Science, Department of Ecology, Environment and

9 Evolution, Centre for Freshwater Ecosystems, Albury/Wodonga Campus, Vic, Australia

10 3. Instituto Nacional de Pesquisas da Amazônia (INPA), Laboratório de Ecofisiologia e 11 Evolução Molecular, Manaus, AM, 69067-375, Brasil

12 Corresponding author : François-Étienne Sylvain, email: francois-etienne.sylvain.1@ulaval.ca

13 Competing interests : The authors declare no competing interests. 


\section{Abstract}

25 The Amazon River basin sustains dramatic hydrochemical gradients defined by three water

26 types: white, clear and black waters. Black waters contain important loads of allochthonous

27 humic dissolved organic carbon (DOC), mostly coming from bacteria-mediated lignin

28 degradation, a process that remains understudied. Here, we identified the main bacterial taxa

29 and functions associated with contrasting Amazonian water types, and shed light on their

30 potential implication in the lignin degradation process. We performed an extensive field

31 bacterioplankton sampling campaign from the three Amazonian water types, and combined our

32 observations to a meta-analysis of 90 Amazonian basin shotgun metagenomes used to build a

33 tailored functional inference database. We showed that the overall quality of DOC is a major

34 driver of bacterioplankton structure, transcriptional activity and functional repertory. We also

35 showed that among the taxa mostly associated to differences between water types,

36 Polynucleobacter sinensis particularly stood out, as its abundance and transcriptional activity

37 was strongly correlated to black water environments, and specially to humic DOC concentration.

38 Screening the reference genome of this bacteria, we found genes coding for enzymes

39 implicated in all the main lignin degradation steps, suggesting that this bacteria may play key

40 roles in the carbon cycle processes within the Amazon basin. 


\section{Introduction}

50 The Amazon basin occupies almost $38 \%$ of continental South America [1] and holds $17 \%$ of the

51 planet's freshwater [2]. Its discharge carries a significant load of terrestrially-derived nutrients to

52 the ocean, which have global consequences on marine primary productivity and global carbon

53 sequestration [3, 4]. The Amazon River basin sustains dramatic hydrochemical and ecological

54 gradients that impose physiological constraints upon its aquatic communities [5-10]. Its three

55 major tributaries, the Rio Solimões, Rio Negro, and Rio Tapajos, represent distinct water 'types'

56 or 'colors', which harbor contrasting physicochemical profiles [11]. The white water from the Rio

57 Solimões has an Andean origin, is eutrophic (nutrient- and ion-rich), turbid, and has a

58 circumneutral $\mathrm{pH}[11-14]$. The crystalline 'clear water' from the Rio Tapajos has a circumneutral

$59 \mathrm{pH}$, low conductivity, and a reduced amount of suspended material associated to its pre-

60 Cambrian origin draining the Brazilian shield. Lastly, the black water of the Rio Negro stems

61 from the craton born drainage of the Guyana shield [15] and largely contrasts with the

62 aforementioned tributaries: it is oligotrophic (nutrient- and ion-poor) and contains a high quantity

63 of dissolved organic carbon (DOC) - typically 8-12 $\mathrm{mg} \mathrm{C} \mathrm{L}^{-1}[10]$. DOC from the Rio Negro has a

64 distinctive allochthonous origin, in comparison with Rio Solimões or Rio Tapajos DOC [16].

65 Terrestrial DOC in the Rio Negro is characterized by an enriched load of humic acids - coming

66 from lignin degradation processes - which acidify the entire Rio Negro watershed $(\mathrm{pH} 2.8-5)$,

67 making it a challenging aquatic environment for most aquatic species [17].

69 Overall, the Amazon basin has very low rates of phytoplankton production [18], suggesting that

70 terrestrial DOC is an important carbon source for bacterial growth $[19,20]$. This is especially

71 true in the Rio Negro, where most of the DOC comes from plant decomposition, released in the

72 water following the seasonal flooding of a significant part of the forest [11, 21], which provides a 
73 concentrated input of lignin-derived components in the environment [22]. Lignin is naturally

74 recalcitrant to degradation $[23,24]$, since its role is to prevent microbial enzymes from

75 degrading labile cell-wall polysaccharides [25]. However, heterotrophic microbes are able to

76 degrade up to $\sim 55 \%$ of the lignin produced by the rainforest [26, 27]. The first step of bacterial

77 lignin degradation is the oxidation of lignin-derived compounds, producing a complex mixture of

78 aromatic compounds, which represent the humic fraction of the DOC detected in the Rio

79 Negro's black water [21, 28].

80 Despite its relevance for global-scale elemental cycling and primary production processes, there

81 is a limited understanding of the taxonomical and functional structure of the Amazon River

82 microbiome [20]. Also, the transcription profile of taxa involved in Amazonian black water lignin

83 degradation processes has yet to be investigated. In this study, we aimed (1) to identify the

84 most important environmental variables shaping the Amazonian bacterioplankton community

85 structural, transcriptional, and functional profiles; and (2) to better understand the interaction

86 between humic DOC and microbial consortia, by highlighting the taxa likely involved in the lignin

87 degradation process and the potential pathways of degradation they possess.

Methods

1. Sampling and processing

91 Water samples were collected from 15 sites in the Brazilian Amazon basin between September-

92 December 2018 and 2019. The 15 sites were distributed over an area of $>300,000 \mathrm{~km}^{2}$ along

93 the Rio Negro, Rio Solimões and Rio Tapajos watersheds, the three major tributaries of the

94 Amazon River [11]. GPS coordinates and a map of all sites are found in Table 1 and Fig. 1,

95 respectively. The 15 sites include five black water, seven white water, and three clear water

96 sites. Six replicate water samples were collected per site. Surface water samples were taken at 
97 a depth of $30 \mathrm{~cm}$ in $2 \mathrm{~L}$ Nalgene $^{\mathrm{TM}}$ (Thermo Fisher Scientific, Waltham (MA) USA) bottles.

98 Filtration was performed as in [29] through $22 \mu \mathrm{m}$-pore size polyethersulfone Sterivex ${ }^{\mathrm{TM}}$ filters

99 (cat \#SVGP01050, Millipore, Burlington (MA), USA) less than 30 minutes after collection. Filters

100 were stored in $2 \mathrm{~mL}$ of NAP conservation buffer [30, 31] immediately upon collection, and then

101 stored in $-80^{\circ} \mathrm{C}$ until processing. Before DNA/RNA extraction, Sterivex ${ }^{\mathrm{TM}}$ filter casings were

102 opened and processed according to [30] using sterile instruments, and filter membranes were

103 stored in TRIzol ${ }^{\mathrm{TM}}$ (cat \#15596026, Thermo Fisher Scientific). DNA and RNA extractions

104 were performed according to the manufacturer's instructions of $\mathrm{TRI}^{\mathrm{T}} \mathrm{I}^{\mathrm{TM}}$ without modification.

105 Four blank controls (sterile filters stored in the NAP buffer) were also processed identically to all

106 samples for DNA/RNA extractions.

107

2. Environmental variables

109 A total of 34 environmental variables were measured in this study (see Table 1, Suppl. Table 1,

$1102,3)$. Temperature $\left({ }^{\circ} \mathrm{C}\right)$, conductivity $(\mu \mathrm{S}), \mathrm{pH}$ and dissolved oxygen $(\%)$ were measured directly

111 on site using a YSI professional plus series multimeter (YSI Inc/Xylem Inc, Yellow Springs $(\mathrm{OH})$,

112 USA). The concentration of DOC, dissolved metals, nutrients, free ions and primary production

113 (i.e. chlorophyll a) were measured at the laboratory, according to the techniques described in

114 details in Suppl. mat. DOC quality was measured using Fluorescence excitation emission

115 (FEEM) scans and modelled using parallel factor analysis (PARAFAC) (see Suppl. mat.).

\section{3. Data availability}

118 The datasets generated and analysed during the current study can be found in the Sequence

119 Read Archive (SRA) repository, BioProjectIDs: PRJNA736442 and PRJNA736450. Accession

120 numbers of the 90 metagenomes used to build the custom database are in Suppl. mat. The

121 scripts used for the DNA/RNA sequence analysis, as well as all related input files including all

122 metadata are freely available on the Open Science Network platform (URL: https://osf.io/dz6vf/). 


\section{4. $16 \mathrm{~S}$ sequence analysis}

125 Microbial community structure and expression were assessed using a 16S rRNA approach

126 conducted on DNA and RNA extracts. Retrotranscription of the RNA extractions was done using

127 the qScript cDNA synthesis kit (cat \#95048-100) from QuantaBio (Beverly (MA), USA) according

128 to the manufacturer's instructions. Then, the fragment V3-V4 ( 500 bp) of the 16S rRNA gene

129 was amplified in DNA and cDNA extracts by PCR using the forward primer 347F (5'-

130 GGAGGCAGCAGTRRGGAAT-3') and the reverse primer 803R (5'-

131 CTACCRGGGTATCTAATCC-3') [32]. The PCRs were performed according to the

132 manufacturer's instructions of the QIAGEN ${ }^{\circledR}$ Multiplex PCR kit (cat \#206143, Hilden, Germany)

133 using an annealing temperature of $60^{\circ} \mathrm{C}$ and 30 amplification cycles. Amplified DNA was

134 purified with AMPure beads (cat \#A63880, Beckman Coulter, Pasadena (CA), USA), according

135 to the manufacturer's instructions, to eliminate primers, dimers, proteins, and phenols. Post-

136 PCR DNA concentration and quality were assessed on a Qubit ${ }^{\mathrm{TM}}$ instrument (Thermo Fisher

137 Scientific) and by electrophoresis on $2 \%$ agarose gels. After purification, multiplex sequencing

138 was performed on Illumina MiSeq by the Plateforme d'Analyses Génomiques at the Institut de

139 Biologie Intégrative et des Systèmes of Université Laval.

140 After sequencing, 24,341,734sequences were obtained (mean of 135,232 sequences per 141 sample). DADA2 [33] was used for amplicon sequence variant (ASV) picking. Details on 16S

142 sequence processing including ASV picking and decontamination using control samples is

143 included in Suppl. mat. An analysis of Shannon diversity according to sampling depth for each

144 sample can be found in Suppl. Fig. 1 and 2. ASV tables, metadata files and taxonomy 145 information were incorporated into phyloseq objects [34] before downstream analyzes.

\section{5. Shotgun metagenome functional database}


147 We built a reference metagenomic database to infer the functional profile of the microbial 148 communities previously characterised using the 16S rRNA approach. The reference database 149 was built from 90 metagenomes from the Amazon River, sampled in previous studies [20, 35150 38]. Details on the shotgun metagenomic database construction can be found in Suppl. mat.

6. Statistical analysis

6.1 Objective \#1: Identify the environmental variables shaping the structural, transcriptional and functional profiles of Amazonian bacterioplankton.

155 First, we aimed to understand to what extent environmental conditions drive the phylogenetic 156 structure, the transcriptional profile and the functional repertory of Amazonian bacterioplankton 157 communities. To do so, we computed Non-metric multidimensional scaling (NMDS) ordinations 158 based on unweighted Unifrac distances [39] between communities (Fig. 2). Biological replicates 159 from every site were merged before this analysis for ease of viewing in the NMDS plot. All the 16034 environmental parameters were fitted to the ordinations using envfit from vegan [40], 161 however, only the 10 parameters with the strongest $R^{2}$ values were kept for plotting. Ellipses 162 showing a 95\% confidence interval were plotted with ordiellipse [40]. Permutational Analyses of 163 Variance (PERMANOVA) were performed with adonis [40] to test the presence of significant 164 difference between water types.

166 Then, we aimed to identify which taxa were associated with the variations in environmental 167 parameters between water types. Although white and clear waters have different origins [11], 168 we decided to merge them together for this analysis, since they show similar environmental 169 parameter profiles in comparison to black water (Table 1, Suppl. Table 1, 2, 3, Suppl. Fig.3). 170 Also, further analyzes focusing on DOC show a unique humic DOC signature in black water in 171 comparison to the other water types. Thus, we were mostly interested in highlighting taxa 172 associated with black water environments rather than to the other water types. We used a 
173 machine-learning approach to identify the taxa that best discriminated black versus white/clear

174 waters. To do so, we implemented Breiman's Random Forest algorithm for classification [41]

175 using randomForest [42] with ntree $=100$. This algorithm splits data in a training and a test set -

176 the training set is used to construct consensus trees of classification via bootstrapping, and the

177 test set $(\approx 37 \%$ of the samples) is then used to estimate the node error rates in the trees of

178 classification (i.e. the out-of-bag estimate of error). We isolated the 40 ASVs responsible for the

179 most important mean decrease in GINI coefficient (measure of node purity) with significant $p$ -

180 values following Bonferroni correction. These ASVs comprised the 40 taxa that best

181 discriminated black versus white/clear waters (with the lowest classification error rate) in the

182 random forest tests. The abundance or the transcriptional activity of these taxa in all samples

183 was represented on heatmaps (Fig. 3) along the strength of their GINI coefficient decrease

184 score.

\subsection{Objective \#2: Understand the interaction between humic DOC and microbial} consortia.

188 We first characterized the overall DOC quality in the sampled environments using Principal

189 Components Analysis (PCA) (Fig. 4a), PARAFAC model components (Fig. 4b) and FEEM

190 scans (Suppl. Fig. 5 in Suppl. Mat.). Then, to better understand the interaction between humic

191 DOC and bacterioplankton communities, we assessed to what extent humic DOC drives

192 community assemblies and transcription profiles. We fitted the humic DOC concentration on

193 NMDS plots (Fig. 5a,b) based on unweighted Unifrac distances using ordisurf [40]. Then, we

194 assessed the Spearman correlations between the humic DOC concentration and the abundance

195 or transcription of bacterial ASVs (Fig. 5c,d). Correlations $>0.5$ with p-value $<0.05$ (after

196 Bonferroni correction) were plotted on Cytoscape v. 3.7.1. We also aimed to identify the

197 potential pathways of lignin degradation present in our dataset. To do so, we performed a

198 comprehensive literature search to list the potential pathways/enzymes currently known to be 
199 involved in lignin degradation in bacteria (see list of enzymes in Suppl. Table 4). We searched

200 for the presence of these enzymes in our dataset using our functional database. When these

201 enzymes were observed to correlate with the concentration of humic DOC, we plotted their

202 abundance and the abundance of the taxa in which they were found using a heatmap (Fig. 6).

203 Finally, based on our results concerning the taxon Polynucleobacter sinensis, we investigated

204 whether the presence of the genes coding the enzymes from Suppl. Table 4 would be found in

205 its reference genome [43] (SRA accession \#: PRJNA295472). We processed the reference

206 bacterial genome as previously described for the reference metagenome, to obtain a list of all

207 pathways/enzymes inventoried.

\section{Results}

Objective \#1: Identify the environmental variables shaping the structural, transcriptional and functional profiles of Amazonian bacterioplankton.

212 Bacterioplankton communities significantly clustered according to water type for structural,

213 transcriptional and functional NMDS analyzes (Fig. 2a,b,c). In all cases, PERMANOVA analyzes

214 consistently showed that water type significantly drove community structure $(\mathrm{F}=8.5$, df.res $=$

$\left.21582, R^{2}=0.17, p<0.001\right)$, transcription profile $\left(F=2.9\right.$, df.res $\left.=82, R^{2}=0.06, p<0.001\right)$, and

216 functional repertory $\left(F=11.8\right.$, df.res $\left.=82, R^{2}=0.22, p<0.001\right)$. NMDS plots from Fig. 2a,b,c

217 also suggest that white and clear water communities were similar, and differed notably from

218 black water communities which form an independent cluster. The top 10 parameters that

219 influenced the structure, transcriptional profile and functional repertory were not identical.

220 However, they always comprised at least one parameter associated with DOC quantity/quality,

221 as well as several parameters associated to the environmental ionic profile (i.e. conductivity or

222 the concentration of specific free ions). 
224 We succeeded in implementing a machine-learning Random Forest algorithm to identify which

225 taxa best discriminated black versus white/clear waters. The out-of-bag error rate (node error

226 rates in the trees of classification) was only $2.35 \%$ when considering community structure, and it

227 was $18.82 \%$ when considering the transcriptional profile. The taxa that best discriminated water

228 types were associated to either black or white/clear waters. Strength of association to water

229 type was stronger for taxa associated to black water than to white/clear waters, especially when

230 looking at the transcriptional profile (Fig. 3b). This was also true for functions in the functional

231 repertory (Suppl. Fig. 4 in Suppl. mat.). Detailed description of the ASV clusters discriminating

232 water types can be found in Suppl. mat. Taxa showing the strongest decrease of GINI

233 coefficient (i.e. the best association score, or discriminating power) at the structural level were

234 two species of Gammaproteobacteria, which were both associated to black waters. At the

235 transcriptional level, the strongest signal came from a group of Polynucleobacter sinensis, also

236 strongly associated to black waters. consortia.

240 The DOC quality varied significantly within the different water types of the Amazon Basin (Fig.

241 4a). The PARAFAC model showed that the DOC was composed of three main fractions: humic-

242 like, fulvic-like and protein-like fractions (Fig. 4b,c,d). Black water sites contained higher

243 amounts of DOC, enriched in humic-like DOC of a greater aromaticity and molecular weight.

244 White water sites contained DOC characterized by a high content of fulvic-like components,

245 while clear water sites contained more protein-like DOC of low aromaticity and molecular weight

246 (see Table 1 for raw data, Fig. 4 and FEEM scans on Suppl. Fig. 5 in Suppl. mat.).

247 The humic-like fraction of DOC was associated to the bacterioplankton community composition

248 and transcription profiles within the different waters of the Amazon basin, as the humic DOC

249 concentration isolines respect the natural clustering of the communities on the unweighted 
250 Unifrac NMDS plots from Fig 5a,b. A co-abundance Spearman correlation network-based

251 approach enabled us to identify which taxa correlated to humic DOC (Fig. 5c,d). The results at

252 the structure and transcriptional levels show different correlation profiles. Indeed, at the

253 structural level, the results suggested a direct correlation between humic DOC concentration

254 and 44 taxa. In contrast, at the transcriptional level, the influence seemed to be mostly indirect

255 since there was only 3 taxa directly correlated to humic DOC concentration. However, these

256 three taxa (two Polynucleobacter sinensis and one Acetobacteraceae) were key in the overall

257 community transcription profile - they were important interaction hubs as their activity was

258 strongly correlated to 93 other taxa.

260 We recomputed the Spearman correlation analysis (between humic DOC and bacterial taxa)

261 after agglomerating all ASVs at the genus level, to ensure compatibility with the metagenome

262 reference database. Several taxa that were significantly associated to humic DOC at the genus

263 level were also associated with humic DOC at the ASV level (e.g. Polynucleboacter and

264 Methylocystis). We investigated the presence/absence of the enzymes known to be part of

265 lignin degradation pathways (see Suppl. Table 4) in the subset of all genera which abundance

266 correlated to humic DOC (Fig. 6). Three genera were highly correlated with humic DOC:

267 Polynucleobacter, Methylobacterium, and Acinetobacter. These three genera also possessed

268 enzymes involved in the four main steps of lignin degradation.

270 Overall, the taxa Polynucleobacter sinensis has shown the most promising results concerning

271 its potential implication in the degradation of lignin-derived compounds/humic DOC. Indeed, the

272 Random-Forest analysis has shown that $P$. sinensis is the best taxa to discriminate black from

273 white/clear waters at the transcriptional level (Fig. 3b). P. sinensis ASVs abundance was

274 correlated to humic DOC concentration in structural and functional profiles (where they

275 represented two out of three ASVs correlated to humic DOC) (Fig. 5c,d). When the correlation 
276 analysis was performed at the genus level, Polynucleobacter was the taxa which abundance

277 showed the strongest correlation to humic DOC (Fig. 6). Finally, Polynucleobacter was involved

278 in the four main lignin degradation steps. Thus, we investigated whether the presence of the

279 genes coding the enzymes from Suppl. Table 4 would be found in the $P$. sinensis reference

280 genome published by Hanh et al. (2009) [43]. We found that $P$. sinensis actually possesses the

281 lignin-degradation enzymes that were found in the reference metagenome, which confirmed our

282 result from Fig. 6 at the genus level. $P$. sinensis possesses genes coding for enzymes involved

283 in the four steps of lignin degradation: initial oxidation, funneling, O-demethylation, and ring

284 cleavage pathways. In brief, the set of genes found in $P$. sinensis genome suggests that it uses

285 a derivative of the $\beta$-aryl ether degradation pathway for diaryl lignin residues, which concludes in

286 an extradiol 4,5-PCA ring meta cleavage producing pyruvate and oxaloacetate. Further details

287 and inference of possible degradation pathways in $P$. sinensis, as well as details on the

288 presence of lignin degradation pathways in non bacterial sequences from the metagenome

289 database can be found in Suppl. mat.

\section{Discussion}

292 Water type shapes bacterial community composition, transcriptional activity, and

293 functional potential.

294 Water type has been shown to be a major driver of the diversity, composition and population

295 genomics of eukaryotic biological communities in Amazonia. This has been shown in a vast

296 array of species including teleosts [44-47], phyto and zooplankton [48], as well as periphyton

297 communities [49]. There has also been a few studies focused on Amazonian bacterioplankton,

298 although most of them did not sample in different water types [20, 35- 38, 50-54]. The

299 aforementioned studies were mostly focused on the dynamics of bacterial communities in the

300 plume downstream of the Amazonian river system [38, 50, 51], or included a very limited 
301 number of sampling sites (e.g. only 1 site in [52]), or solely relied on taxonomic approaches, 302 without considering the transcriptional activity of taxa involved [35- 37, 52-54]. In our study, we 303 used an unprecedented approach combining data from the structure, transcription activity and 304 functional repertory of 15 bacterioplankton communities from the three water types of the upper 305 Amazonian basin. We were also the first to characterize extensively the environments sampled 306 (34 parameters measured, from physicochemical parameters to primary productivity, ionic 307 profiles, detailed DOC quality analyses, etc.) which enabled us to identify accurately which 308 variables were most likely involved in shaping Amazonian bacterioplankton.

309 Our results showed an important influence of water type on bacterioplankton structure, 310 transcription and functional profiles (Fig. 2). For all these profiles (Fig. 2a,b,c), we showed that 311 among the 10 environmental parameters that were the most associated with community 312 clustering, several are known to be the main parameters driving differences between water 313 types. For instance, higher concentrations of total $\mathrm{DOC}$, humic $\mathrm{DOC}, \mathrm{Al}$ and $\mathrm{Pb}$ are known to be 314 strongly associated with black waters [16,55], while higher primary productivity (chlorophyll a), 315 conductivity, and $\mathrm{pH}$ are characteristic of white and clear water environments. Interestingly, we 316 observed that the clustering of functional repertory according to water types (Fig. 2c) was not as 317 clear as structural or transcriptional profiles clusterings (Fig. 2a,b). This result might be 318 associated to the fact that several house-keeping genes are shared by all bacterial members, 319 thus reducing inter-site variability when considering the functional repertories. However, based 320 on the significant PERMANOVA results (Fig. 3c) it still appears that there were significant water-

321 type-specific functional profiles. Additionally, the Random-Forest analysis also identified 40 322 functions which have strong predictive capability in a black versus white/clear water model 323 (Suppl. Fig. 4 in Suppl. mat.).

325 An aspect that should be considered when analyzing the functional profiles from a tailored 326 metagenomic database is the limitation of inferring functional repertoires from 16S rRNA 
327 sequence based ASVs, in comparison to using a shotgun metagenomic approach for each

328 bacterioplankton sample [56, 57]. Although our approach is analog to current functional

329 inference pipelines such as PiCRUST [57], it palliates to an important caveat of these pipelines

330 concerning the fact that they were designed primarily for human microbiome research, and thus

331 lack the depth needed for thorough and precise characterization of aquatic bacterioplankton

332 functions [56]. However, the main downfall of any approach using taxonomy to infer functions is

333 that the completeness of the inferred functional profiles relies on the accuracy of taxonomical

334 assignations, which are not always fully resolved in understudied environments like the

335 Amazonian basin [20].

337 An interesting result emerging from the Random-Forest analysis (Fig. 3 and Suppl. Fig. 4) is the

338 fact that the strength of association of taxa or functions to black water environments was

339 stronger and more consistent than associations to the white/clear water environments. Indeed,

340 the taxa/functions that best discriminated water types were mostly found to be associated to

341 black water environments, which suggests that black water communities have transcriptional

342 activities and functional repertories that are more specific than white/clear water sites which

343 showed higher inter-site variability. This result concords with the fact that black water is an

344 "extreme" environment offering challenging physicochemical conditions for biological processes,

345 i.e. acidic $\mathrm{pH}(2.8-5.0)$ and very low conductivity $(\approx 10 \mu \mathrm{S})$ [11]. Adaptation to these conditions

346 potentially necessitates the presence and transcription of certain key functions, which constitute

347 a unique signature/profile of these communities due to their omnipresence in these

348 environments. Several studies have focused on how microorganisms populating extreme

349 environments cope with stress $[58,59]$. Most have found that genome plasticity, including codon

350 bias, nucleotide skew and horizontal gene transfers (HGTs), enable evolutionary adaptation to

351 extreme conditions [60-62]. For most bacteria, adaptation to extreme environments is a highly

352 dynamic and complex process that involves multiple evolutionary forces [63, 64]. Although not 
353 tested in this study, these forces could potentially drive the appearance of a consistent

354 signature/profile found in the microbiomes from similar hostile environments such as black

355 waters from different sites.

\section{Humic DOC and bacterioplankton communities}

358 Dissolved organic carbon forms the very basis of the majority of aquatic food webs and is an

359 important food source to heterotrophs within river systems $[65,66]$. The bioavailability of DOC to

360 bacterioplankton depends on the type of DOC present. It has been suggested that

361 allochthonous humic-like DOC may be more bioavailable to bacteria than lower molecular

362 weight DOC [67] and that some bacteria prefer terrestrially derived DOC over autochthonous

363 protein-like DOC derived from algae and/or bacteria (Roiha et al. 2016). Previous research has

364 shown that bacteria are able to breakdown humic DOC, supporting the idea that this component

365 is bioavailable to some bacterial species $[67,68]$. Our analysis of DOC quality from the 15 sites

366 showed that black waters have distinct DOC profiles, with higher concentrations of DOC,

367 comprising a significant enrichment in the humic fraction characterized by higher SAC340 and

368 SUVA254 scores (table 1 and Fig. 4). These results support previous findings by Holland et al.

369 (2018) which suggest that naturally acidic waters show a unique DOC signature when

370 compared to circumneutral and groundwater fed systems. Multivariate correlation analyzes also

371 suggested that the concentration of humic DOC is an important factor shaping the structure and

372 transcriptional activity (Fig. 2 and 5) of Amazonian bacterioplankton. Furthermore, analyzes at

373 the functional level showed that there are several taxa in the Amazonian bacterioplankton

374 community which abundance correlates with humic DOC, and which possess genes associated

375 with lignin degradation processes. Overall, the taxa Polynucleobacter sinensis has shown the

376 most promising results concerning its potential implication in the degradation of lignin-derived

377 compounds within humic DOC. Indeed, the Random-Forest analysis showed that $P$. sinensis

378 was the best taxa to discriminate black from white/clear waters at the transcriptional level (Fig. 
379 3b). Polynucleobacter sinensis ASVs abundance and activity were also strongly correlated to 380 humic DOC concentration (Fig. 5c,d).

382 The genus Polynucleobacter mostly comprises free-living aquatic bacteria and has been

383 reported in numerous freshwater lakes and ponds [69]. Several studies have detected a strong 384 correlation between the abundance of this genus and DOC concentration [69-71]. Some of 385 these reports suggest that Polynuclebacter can feed on dissolved organic matter [70-71]. 386 However, up to now the implication of this clade in humic carbon degradation in Amazonia has 387 yet to be investigated. Here, we searched the reference genome of $P$. sinensis [43], the taxa 388 found to correlate most reliably with humic DOC concentration, for genes coding for enzymes 389 known to play key roles in the lignin degradation process. Interestingly, we report for the first 390 time that the genome of $P$. sinensis contains genes for key enzymes from the four steps of the 391 lignin degradation process, i.e. initial oxidation, funneling, O-demethylation, and ring cleavage 392 pathways. However, since not all enzymes required for each pathway were detected in its 393 genome, further studies are needed to decipher exactly if and how this bacterium degrades 394 lignin, and to determine whether it is able to perform this process alone, or with associations 395 (e.g. via syntrophic interactions) with other members of the bacterioplankton community, or with 396 non-bacterial microbes. For instance, in the metagenomic reference database used for our 397 study, we detected the presence of the gene ligD in several bacterial species but not in $P$. 398 sinensis (Fig. 6). This gene was also detected in two fungi (Aureobasidium and Ascomycota).

399 This enzyme catalyzes the oxidation of guaiacylglycerol-b-guaiacyl ether, one of the first steps 400 of the $\beta$-aryl ether lignin degradation pathway for which $P$. sinensis possess several other 401 enzymes. Although not tested here, functional compartmentalization of the community for lignin 402 degradation has already been documented [72], and could potentially involve inter-kingdom 403 relationships via alternative pathways that remain to be discovered (reviewed in [73, 74]). 
404 Finally, further studies should also assess if bacterial DOC degradation in Amazonia is 405 dependent on a coupling with physical photodegradation processes, as suggested by Nalven et 406 al. (2020) [75].

\section{Conclusion}

409 Our study provides the first insights into the factors shaping the taxonomical, transcriptional and

410 functional profiles of Amazonian bacterioplankton communities. Our comprehensive approach

411 combined observations from bacterioplankton samples collected from 15 sites across the

412 Amazon basin, to a meta-analysis of 90 Amazonian shotgun metagenomes used to build a

413 functional reference database. The results show that the most important factors affecting these

414 bacterioplankton communities within the three different water types of the Amazon basin are

$415 \mathrm{DOC}$, humic $\mathrm{DOC}, \mathrm{Pb}$ and $\mathrm{Al}$ concentrations, which are all associated to black water

416 environments. We also used a novel Random-Forest approach to highlight the taxa mostly

417 associated to the observed differences between water types. Among these taxa, ASVs assigned

418 to the species Polynucleobacter sinensis particularly stood out, as their abundance and their

419 transcriptional activity were strongly correlated to black water environments, and specially to

420 humic DOC concentration. Screening the reference genome of this bacteria, we found genes

421 coding for enzymes implicated in all the main lignin degradation steps, which suggest that this

422 bacteria may play a significant role in this important process key to carbon cycling in the 423 Amazonian basin.

\section{Acknowledgements}


426 We thank the National Geographic Society, NSERC, MITACS, and Ressources Aquatiques

427 Québec for awarding travel grants to FÉS. This study was part of the NSERC Discovery grant of

428 ND, the INCT ADAPTA project of ALV, and supported by a Canada-Brazil Awards - Joint

429 Research Project of ND and ALV, by CNPq, FAPEAM and CAPES. We thank Thiago

430 Nascimento, Reginaldo Oliveira and Nazaré Paula for technical support with field work logisitcs.

431 We thank Roxanne Dhommée for support in the molecular biology laboratory work. Finally, we

432 thank the anonymous reviewers that generously took the time to help improve this manuscript.

\section{Competing Interests}

435 The authors declare no competing interests.

\section{References}

438 1. Mikhailov VN. Water and sediment runoff at the Amazon River mouth. Water Resources.

$439 \quad 2010 ; 37(2): 145-59$.

440 2. Maretti CC, Riveros SJC, Hofstede R, Oliveira D, Charity S, Granizo T, et al. (eds). State of

441 the Amazon: Ecological Representation in Protected Areas and Indigenous Territories.

442 (Brasília and Quito: WWF Living Amazon (Global) Initiative. 2014).

443 3. Richey JE, Nobre C, Deser C. Amazon river discharge and climate variability - 1903 to 1985.

$444 \quad$ Science. 1989;246(4926):101-3.

445 4. Subramaniam A, Yager PL, Carpenter EJ, Mahaffey C, Bjorkman K, Cooley S, et al. 446 Amazon River enhances diazotrophy and carbon sequestration in the tropical North Atlantic 447 Ocean. Proceedings of the National Academy of Sciences of the United States of America. $448 \quad 2008 ; 105(30): 10460-5$. 
5. Junk WJ, Soares MG, Carvalho FM. Distribution of fish species in a lake of the Amazon River floodplain near Manaus (Lago Camaleão), with special reference to extreme oxygen conditions. Amazoniana. 1983;397-431.

6. Henderson PA, Crampton WGR. A comparison of fish diversity and abundance between nutrient-rich and nutrient-poor lakes in the Upper Amazon. Journal of Tropical Ecology. 1997;13:175-98.

7. Rodriguez MA, Lewis WM. Structure of fish assemblages along environmental gradients in floodplain lakes of the Orinoco River. Ecological Monographs. 1997;67(1):109-28.

8. Saint-Paul U, Zuanon J, Correa MAV, Garcia M, Fabre NN, Berger U, et al. Fish communities in central Amazonian white- and blackwater floodplains. Environmental Biology of Fishes. 2000;57(3):235-50.

9. Petry P, Bayley PB, Markle DF. Relationships between fish assemblages, macrophytes and environmental gradients in the Amazon River floodplain. Journal of Fish Biology.

463 10. Duarte RM, Smith DS, Val AL, Wood CM. Dissolved organic carbon from the upper Rio Negro protects zebrafish (Danio rerio) against ionoregulatory disturbances caused by low pH exposure. Scientific Reports. 2016;6.

11. Sioli H (eds). The Amazon Limnology and Landscape Ecology of a Mighty Tropical River and its Basin. (Dr. Junk Publisher, Dordrecht, 1984).

471 13. Gaillardet J, Dupre B, Allegre CJ, Negrel P. Chemical and physical denudation in the 472 Amazon River basin. Chemical Geology. 1997;142(3-4):141-73.

473 14. Val AL, Almeida-Val VMF (eds). Fishes of the Amazon and Their Environment. (Springer$474 \quad$ Verlag Berlin Heidelberg, 1995). 
475 15. Hoorn C, Wesselingh FP, ter Steege H, Bermudez MA, Mora A, Sevink J, et al. Amazonia

476 Through Time: Andean Uplift, Climate Change, Landscape Evolution, and Biodiversity.

$477 \quad$ Science. 2010;330(6006):927-31.

478 16. Holland A, Wood CM, Smith DS, Correia TG, Val AL. Nickel toxicity to cardinal tetra

479 (Paracheirodon axelrodi) differs seasonally and among the black, white and clear river $480 \quad$ waters of the Amazon basin. Water Research. 2017;123:21-9.

481 17. Araujo JDA, Ghelfi A, Val AL. Triportheus albus Cope, 1872 in the Blackwater, Clearwater, 482 and Whitewater of the Amazon: A Case of Phenotypic Plasticity? Frontiers in Genetics. $483 \quad 2017 ; 8$.

484 18. Wissmar RC, Richey JE, Stallard RF, Edmond JM. Plankton metabolism and carbon 485 processes in the Amazon river, its tributaries, and floodplain waters, Peru-Brazil, May-June 1977. Ecology. 1981;62(6):1622-33.

487 19. Mayorga E, Aufdenkampe AK, Masiello CA, Krusche AV, Hedges JI, Quay PD, et al. Young organic matter as a source of carbon dioxide outgassing from Amazonian rivers. Nature. 2005;436(7050):538-41 .

20. Santos CD, Sarmento $H$, de Miranda FP, Henrique-Silva F, Logares R. Uncovering the genomic potential of the Amazon River microbiome to degrade rainforest organic matter. Microbiome. 2020;8(1).

21. Ertel JR, Hedges JI, Devol AH, Richey JE, Ribeiro MDG. Dissolved humic substances of the Amazon river system. Limnology and Oceanography. 1986;31(4):739-54.

22. Queiroz MMA, Horbe AMC, Seyler P, Moura CAV. The Solimões river hydrochemistry between Manacapuru and Alvarães: Amazonas - Brazil. Acta Amazonia. 2009;39(4).

498 as inputs to soil organic matter. Soil Biology \& Biochemistry. 2002;34(2):139-62.

499 24. Bugg TDH, Ahmad M, Hardiman EM, Rahmanpour R. Pathways for degradation of lignin in 500 bacteria and fungi. Natural Product Reports. 2011;28(12):1883-96. 
501 25. Janusz G, Pawlik A, Sulej J, Swiderska-Burek U, Jarosz-Wilkolazka A, Paszczynski A.

502 Lignin degradation: microorganisms, enzymes involved, genomes analysis and evolution.

$503 \quad$ Fems Microbiology Reviews. 2017;41(6):941-62.

504 26. Ward ND, Bianchi TS, Sawakuchi HO, Gagne-Maynard W, Cunha AC, Brito DC, et al. The 505 reactivity of plant-derived organic matter and the potential importance of priming effects 506 along the lower Amazon River. Journal of Geophysical Research-Biogeosciences. $507 \quad 2016 ; 121(6): 1522-39$.

508 27. Ward ND, Keil RG, Medeiros PM, Brito DC, Cunha AC, Dittmar T, et al. Degradation of 509 terrestrially derived macromolecules in the Amazon River. Nature Geoscience. $510 \quad 2013 ; 6(7): 530-3$.

511 28. Seidel M, Dittmar T, Ward ND, Krusche AV, Richey JE, Yager PL, et al. Seasonal and 512 spatial variability of dissolved organic matter composition in the lower Amazon River. 513 Biogeochemistry. 2016;131(3):281-302.

514 29. Cruaud P, Vigneron A, Fradette MS, Charette SJ, Rodriguez MJ, Dorea CC, et al. Open the 515 Sterivex (TM) casing: An easy and effective way to improve DNA extraction yields. 516 Limnology and Oceanography-Methods. 2017;15(12):1015-20.

517 30. Camacho-Sanchez M, Burraco P, Gomez-Mestre I, Leonard JA. Preservation of RNA and 518 DNA from mammal samples under field conditions. Molecular Ecology Resources. $519 \quad 2013 ; 13(4): 663-73$.

520 31. Menke S, Gillingham MAF, Wilhelm K, Sommer S. Home-Made Cost Effective Preservation 521 Buffer Is a Better Alternative to Commercial Preservation Methods for Microbiome 522 Research. Frontiers in Microbiology. 2017;8.

523 32. Nossa CW, Oberdorf WE, Yang LY, Aas JA, Paster BJ, DeSantis TZ, et al. Design of 16S 524 rRNA gene primers for 454 pyrosequencing of the human foregut microbiome. World $525 \quad$ Journal of Gastroenterology. 2010;16(33):4135-44. 
526 33. Callahan BJ, McMurdie PJ, Rosen MJ, Han AW, Johnson AJA, Holmes SP. DADA2: High527 resolution sample inference from Illumina amplicon data. Nature Methods. 2016;13(7):581.

528 34. McMurdie PJ, Holmes S. phyloseq: An R Package for Reproducible Interactive Analysis and 529 Graphics of Microbiome Census Data. Plos One. 2013;8(4).

530 35. Santos CD, Kishi LT, Toyama D, Soares-Costa A, Oliveira TCS, de Miranda FP, et al. 531 Metagenome Sequencing of Prokaryotic Microbiota Collected from Rivers in the Upper 532 Amazon Basin. Microbiology Resource Announcements. 2017;5(2).

533 36. Santos CD, Toyama D, de Oliveira TCS, de Miranda FP, Henrique-Silva F. Flood Season 534 Microbiota from the Amazon Basin Lakes: Analysis with Metagenome Sequencing. 535 Microbiology Resource Announcements. 2019;8(17).

536 37. Toyama D, Kishi LT, Santos CD, Soares-Costa A, de Oliveira TCS, de Miranda FP, et al. 537 Metagenomics Analysis of Microorganisms in Freshwater Lakes of the Amazon Basin. 538 Microbiology Resource Announcements. 2016;4(6).

539 38. Satinsky BM, Zielinski BL, Doherty M, Smith CB, Sharma S, Paul JH, et al. The Amazon 540 continuum dataset: quantitative metagenomic and metatranscriptomic inventories of the $541 \quad$ Amazon River plume, June 2010. Microbiome. 2014;2.

542 39. Lozupone C, Lladser ME, Knights D, Stombaugh J, Knight R. UniFrac: an effective distance 543 metric for microbial community comparison. Isme Journal. 2011;5(2):169-72.

544 40. Oksanen JF, Blanchet G, Friendly M, Kindt R, Legendre P, McGlinn D, et al. vegan: 545 Community Ecology Package. R package version 2.5-6. 2019. https://CRAN.R546 project.org/package=vegan

547 41. Breiman L. Random Forests. Mach Learn. 2001;45:5-32.

548 42. Liaw A, Wiener M. Classification and Regression by randomForest. R News. 2002;2(3), 1854922.

550 43. Hahn MW, Lang E, Brandt U, Wu QL, Scheuerl T. Emended description of the genus 551 Polynucleobacter and the species Polynucleobacter necessarius and proposal of two 
subspecies, $P$. necessarius subsp. necessarius subsp nov and $P$. necessarius subsp asymbioticus subsp nov. International Journal of Systematic and Evolutionary Microbiology.

$554 \quad 2009 ; 59: 2002-9$. ecological divergence across an Amazonian ecotone. Evolution. 2014;68(7):1947-60.

45. Beheregaray LB, Cooke GM, Chao NL, Landguth EL. Ecological speciation in the tropics: insights from comparative genetic studies in Amazonia. Frontiers in Genetics. 2015;5.

46. Van der Sleen A, Albert JS (eds). Field guide to the fishes of the Amazon. Orinoco and Guianas. (Oxford University Press, 2018).

47. Bogota-Gregory JD, Lima FCT, Correa SB, Silva-Oliveira C, Jenkins DG, Ribeiro FR, et al. Biogeochemical water type influences community composition, species richness, and biomass in megadiverse Amazonian fish assemblages. Scientific Reports. 2020;10(1).

48. Sahoo PF, Guimaraes JTF, Souza-filho PWM, Bozelli RL, Araujo LR, Menezes RS, et al. Limnological characteristics and planktonic diversity of five tropical upland lakes from Brazilian Amazon. Ann. Limnol. - Int. J. Lim. 2017; 467-483.

49. Putz R. Periphyton communities in Amazonian black- and whitewater habitats: Community structure, biomass and productivity. Aquatic Sciences. 1997;59(1):74-93.

50. Satinsky BM, Smith CB, Sharma S, Landa M, Medeiros PM, Coles VJ, et al. Expression patterns of elemental cycling genes in the Amazon River Plume. Isme Journal. 2017;11(8):1852-64.

576 Metagenomics of the Water Column in the Pristine Upper Course of the Amazon River. Plos 577 One. $2011 ; 6(8)$. 
53. Sylvain FE, Holland A, Bouslama S, Audet-Gilbert E, Lavoie C, Val AL, et al. Fish Skin and Gut Microbiomes Show Contrasting Signatures of Host Species and Habitat. Applied and Environmental Microbiology. 2020;86(16).

54. Sylvain F, Holland A, Audet G, Val AL, Derome N. Amazon fish bacterial communities show structural convergence along widespread hydrochemical gradients. Molecular Ecology. 2019;28(15):3612-26.

55. Holland A, Stauber J, Wood CM, Trenfield M, Jolley DF. Dissolved organic matter signatures vary between naturally acidic, circumneutral and groundwater-fed freshwaters in Australia. Water Research. 2018;137:184-92.

56. Sun S, Jones RB, Fodor AA. Inference-based accuracy of metagenome prediction tools varies across sample types and functional categories. Microbiome. 2020;8(1).

57. Langille MGI, Zaneveld J, Caporaso JG, McDonald D, Knights D, Reyes JA, et al. Predictive functional profiling of microbial communities using 16S rRNA marker gene sequences.

58. Zhou JZ, He Q, Hemme CL, Mukhopadhyay A, Hillesland K, Zhou AF, et al. How sulphatereducing microorganisms cope with stress: lessons from systems biology. Nature Reviews Microbiology. 2011;9(6):452-66.

59. Bang C, Dagan T, Deines P, Dubilier N, Duschl WJ, Fraune S, et al. Metaorganisms in extreme environments: do microbes play a role in organismal adaptation? Zoology. 2018;127:1-19.

60. Zeldovich KB, Berezovsky IN, Shakhnovich El. Protein and DNA sequence determinants of thermophilic adaptation. Plos Computational Biology. 2007;3(1):62-72.

61. Hemme CL, Deng Y, Gentry TJ, Fields MW, Wu LY, Barua S, et al. Metagenomic insights into evolution of a heavy metal-contaminated groundwater microbial community. Isme Journal. 2010;4(5):660-72. 
603 62. Cheaib B, Seghouani H, ljaz UZ, Derome N. Community recovery dynamics in yellow perch

604 microbiome after gradual and constant metallic perturbations. Microbiome. 2020;8(1):14.

605 63. Tyson GW, Chapman J, Hugenholtz P, Allen EE, Ram RJ, Richardson PM, et al. 606 Community structure and metabolism through reconstruction of microbial genomes from the 607 environment. Nature. 2004;428(6978):37-43.

608 64. Allen EE, Tyson GW, Whitaker RJ, Detter JC, Richardson PM, Banfield JF. Genome 609 dynamics in a natural archaeal population. Proceedings of the National Academy of 610 Sciences of the United States of America. 2007;104(6):1883-8.

611 65. Holland A, Duivenvoorden LJ, Kinnear SHW. Naturally acidic waterways: conceptual food 612 webs for better management and understanding of ecological functioning. Aquatic 613 Conservation-Marine and Freshwater Ecosystems. 2012;22(6):836-47.

614 66. Holland A, Mclnerney PJ, Shackleton ME, Rees GN, Bond NR, Silvester E. Dissolved 615 organic matter and metabolic dynamics in dryland lowland rivers. Spectrochimica Acta Part 616 a-Molecular and Biomolecular Spectroscopy. 2020;229.

617 67. Yamashita Y, Fichot CG, Shen Y, Jaffe R, Benner R. Linkages among fluorescent dissolved 618 organic matter, dissolved amino acids and lignin-derived phenols in a river-influenced ocean 619 margin. Frontiers in Marine Science. 2015;2.

620 68. Roiha T, Peura S, Cusson M, Rautio M. Allochthonous carbon is a major regulator to 621 bacterial growth and community composition in subarctic freshwaters. Scientific Reports. $622 \quad 2016 ; 6$

623 69. Jezberova J, Jezbera J, Brandt U, Lindstrom ES, Langenheder S, Hahn MW. Ubiquity of 624 Polynucleobacter necessarius ssp asymbioticus in lentic freshwater habitats of a 625 heterogenous $2000 \mathrm{~km}^{2}$ area. Environmental Microbiology. 2010;12(3):658-69.

626 70. Watanabe K, Komatsu N, Ishii Y, Negishi M. Effective isolation of bacterioplankton genus 627 Polynucleobacter from freshwater environments grown on photochemically degraded 628 dissolved organic matter. Fems Microbiology Ecology. 2009;67(1):57-68. 
629 71. Broman E, Asmala E, Carstensen J, Pinhassi J, Dopson M. Distinct Coastal Microbiome

630 Populations Associated With Autochthonous- and Allochthonous-Like Dissolved Organic

$631 \quad$ Matter. Frontiers in Microbiology. 2019;10.

632 72. Gilmore SP, Lankiewicz TS, Wilken S, Brown JL, Sexton JA, Henske JK, et al. Top-Down

633 Enrichment Guides in Formation of Synthetic Microbial Consortia for Biomass Degradation.

634 Acs Synthetic Biology. 2019;8(9):2174-85.

635 73. de Gonzalo G, Colpa DI, Habib MHM, Fraaije MW. Bacterial enzymes involved in lignin 636 degradation. Journal of Biotechnology. 2016;236:110-9.

637 74. Kamimura N, Takahashi K, Mori K, Araki T, Fujita M, Higuchi Y, et al. Bacterial catabolism of 638 lignin-derived aromatics: New findings in a recent decade: Update on bacterial lignin 639 catabolism. Environmental Microbiology Reports. 2017;9(6):679-705.

640 75. Nalven SG, Ward CP, Payet JP, Cory RM, Kling GW, Sharpton TJ, et al. Experimental 641 metatranscriptomics reveals the costs and benefits of dissolved organic matter photo642 alteration for freshwater microbes. Environmental Microbiology. 2020;22(8):3505-21. 


\section{Table legends}

653 Table 1: Site identification, geographical coordinates, dissolves organic carbon (DOC) quantity

654 and quality characterization. "DOC conc." means DOC concentration in $\mathrm{mg} \mathrm{L}^{-1}$. SAC340 and

655 SUVA254 are the specific absorbance coefficients index of relative DOC aromaticity (higher the

656 values more aromatic is the DOC). Abs254/365 is the index of molecular weight: the lower the

657 value the higher molecular weight is the DOC is.

660 Figure legends

661 Figure 1: Map of the 15 sampling sites distributed throughout the Brazilian Amazon basin. The 662 color of the dots represent the water type (black, white of clear).

664 Figure 2: The structure, transcription and functional profiles of bacterioplankton significantly 665 cluster according to water type. NMDS ordination plots of sampling sites according to the (a)

666 bacterioplankton taxonomic structure, (b) transcriptional profile and (c) functional repertory. 667 Samples $(n=90)$ were merged per sampling site and were colored according to their water 668 type. $\mathrm{P}$ and $\mathrm{F}$ values from the PERMANOVA tests and NMDS stress values are in red; ${ }^{* \star *}$ 669 means $p$-value $<0.001$. Only the 10 environmental parameters showing the strongest 670 association to microbiome data (via envfit) were represented in each plot for ease of viewing.

672 Figure 3: Random-Forest (RF) machine-learning analysis identifies the 40 taxa showing the 673 most important differentiation between black and white/clear water types. Results are shown in 674 heatmaps for the taxonomical structure (a) and the transcriptional profile (b) datasets. Heatmap 675 columns represent samples and rows are different ASVs. The colored shape at the left of each 676 row corresponds to the ASV taxonomic assignation (at the best possible level). RF scores 
677 correspond to the mean decrease of GINI coefficient (higher scores mean a better capacity to

678 discriminate groups).

680 Figure 4: Black water sites showed unique dissolved organic carbon (DOC) quality profiles,

681 characterized by a higher load of aromatic, high molecular weight humic carbon. (a) Principal

682 Components Analysis showing how sampling sites cluster according to their DOC quality

683 profiles. The three bigger dots refer to group centroids. Environmental variables: "DOC" refers to

684 concentration ( $\mathrm{mg} \mathrm{L}^{-1}$ ) of DOC; "protein" refers to concentration of protein-like DOC; "humic"

685 refers to concentration of humic-like DOC; "fulvic" refers to concentration of fulvic-like DOC;

686 SAC340, SUVA254 and abs254.365 refer to absorbance ratios detailed in Table 1. Then,

687 PARAFAC model components showed the presence of humic-like (b), protein-like (c), and

688 fulvic-like (d) DOC fractions in the sites sampled.

690 Figure 5: The concentration of humic dissolved organic carbon (DOC) correlated to

691 bacterioplankton structural and transcriptional profiles' clustering and feature abundance.

692 Ordisurf plots (i.e. NMDS fitted with isolines describing humic DOC concentration variations) for

693 the structural (a) and transcriptional (b) profiles. Samples were merged per sampling site and

694 were colored according to their water type. Spearman correlation-based networks of co-

695 abundance between humic DOC concentrations and bacterial taxa abundance (c) or

696 transcriptional activity (d). For ease of viewing, only the taxa which correlated directly with humic

697 DOC, or that were direct neighbors of such taxa, were kept for network construction. Nodes

698 were colored according to their taxonomic assignation (at the best level possible). In (c,d) black

699 edges represented direct correlations between humic DOC and specific taxa. In (d), edges from

700 the three nodes directly correlated to humic DOC were colored according to their node

701 taxonomic assignation to highlight the indirect effect of humic DOC on the transcriptional profile.

702 These edges were not colored in (c) for ease of viewing. 
704 Figure 6: Potential presence of different pathways of the four main steps of lignin degradation

705 (Kamimura et al. 2017) in the genera which abundance correlated with humic DOC

706 concentration. Spearman correlation between humic DOC and genera abundances were plotted

707 on a heatmap from less to most correlated (left to right respectively). Polynucleobacter is in bold

708 as it is the genus showing the highest correlation to humic carbon concentration. The complete

709 list of pathways that were screened for in the functional repertory can be found in Suppl. Table

7104 , however, only the pathways that were found in at least one genus are represented in the

711 heatmap for ease of viewing. TCA cycle refers to the tricarboxylic acid cycle. 


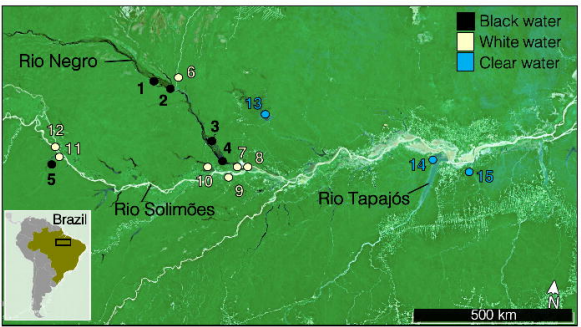



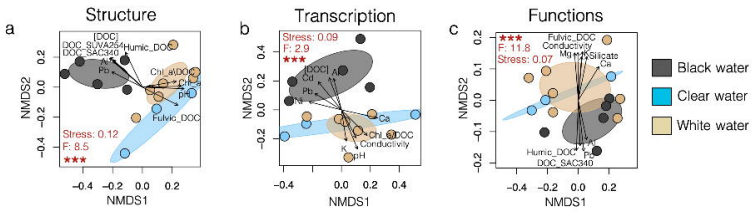
a.

Structure
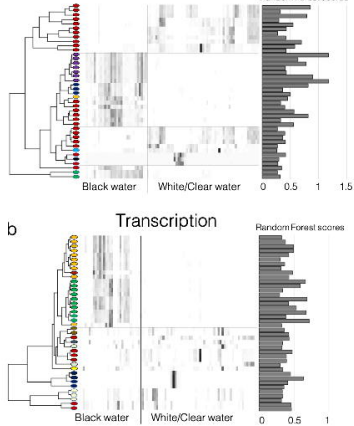

Rendam Forest sxures

\section{Rektive alounderce}

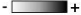

\section{Legend}

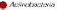

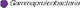

- Eacrera

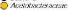

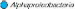

- Busbolitorises

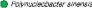

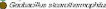

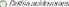

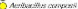

- Branhiziaurnamugrse

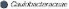

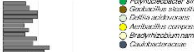


DOC quality analysis

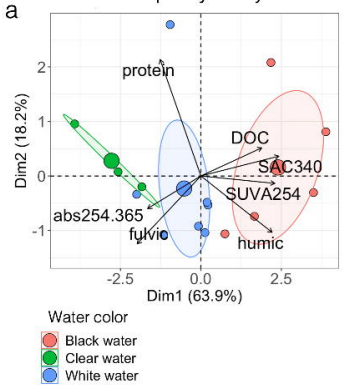

b

\section{model components}

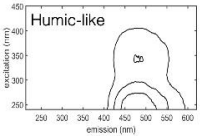

C
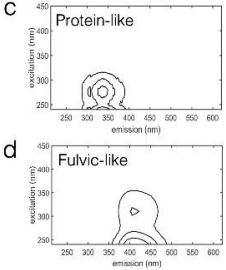
a

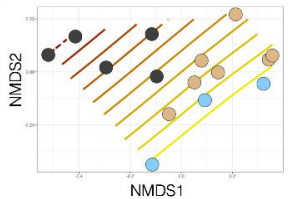

C 2 Humic DOC

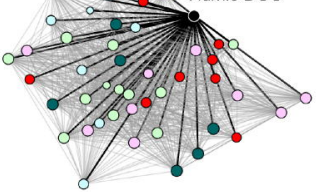

b

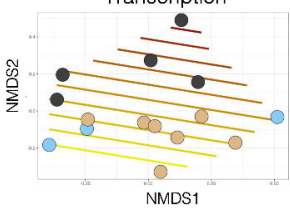

Humic DOC

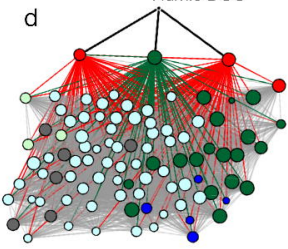

Humic DOC $\mathrm{mg} / \mathrm{L}$

$6 \longdiv { 2 }$

Black water

Clear water

$\bigcirc$ White water

Humic DOC (mg / L)

Acetobacteraceae

Polynucleobacter sinensis

Bacteria

Protoobactoria

Methyiocystis bryophila

Betaproteobacteria

Gammaproteobacteria 


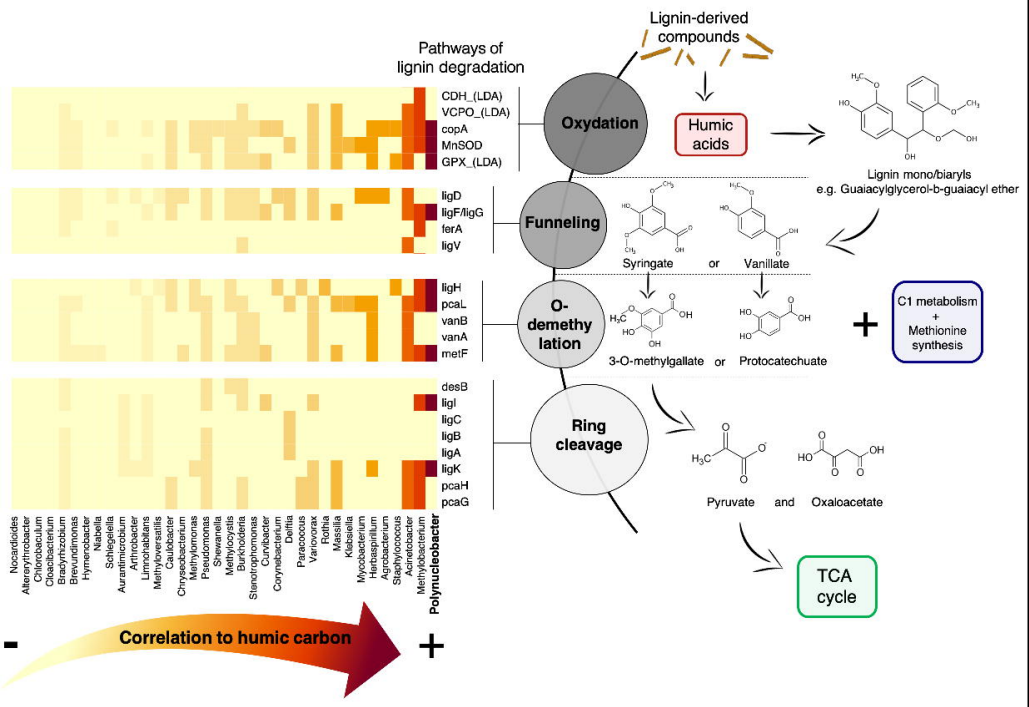

